\title{
TESTOSTERONE LEVELS IN INTERSEX GOATS
}

\author{
G. ZLOTNIK* \\ Department of Physiology, Universidade Católica do Paraná, \\ Curitiba, Paraná, Brasil
}

(Received 30th Fune 1972)

Although sex reversal is fairly common in invertebrates, the presence of male characteristics with a female karyotype in mammals merits a detailed examination.

Four goats of the Toggenburg strain belonging to the Department of Genetics of the Faculdade de Ciencias Medicas e Biologicas of Botucatu, Brasil, with a small vagina, an enlarged penis, a variable degree of labial fusion and a common opening of the urethra and vagina, were found to have a female karyotype. This was established from the chromosomal pattern of cultured leucocytes and sex chromatin studies of brain tissue cells. The same goats were reported to have a male phenotype with a mounting tendency when in the presence of females. Blood samples were taken from these intersex animals and from 'normal' males and females to assess testosterone levels. The intersex animals were examined at autopsy and were found to have a testis-like structure with tubules and epididymis in the presence of a uterus and Fallopian tubes.

A blood sample was obtained from the 'gonadal' vein. Ovaries were not found at the time of autopsy nor after careful histological examination. The adrenals appeared normal.

The testosterone levels in these intersex animals were assessed by a competitive protein-binding method. Since no values for testosterone in normal goats have yet been reported, seven normal females and seven normal males were also studied.

The competitive protein-binding method used was that described by August, Tkachuk \& Grumbach (1969) with minor modifications. Heparinized plasma samples ( $2 \mathrm{ml}$ for male and $6 \mathrm{ml}$ for female specimens) were frozen and sent for assay. For the intersex goats, samples of 3 to $4 \mathrm{ml}$ were used. After adding radioactive tracer $\left(1500 \mathrm{~d} . / \mathrm{min}\left[{ }^{3} \mathrm{H}\right]\right.$ testosterone 40 to $50 \mathrm{Ci} / \mathrm{mm}$, New England Nuclear), $0.1 \mathrm{ml} 4 \mathrm{~N}-\mathrm{NaOH}$ was added and the mixture was extraeted twice with 2 vols freshly distilled ethyl-ether. Purification of the ether extracts was accomplished by thin-layer chromatography. After drying under reduced pressure and concentrating with chloroform, the extracts were spotted onto $20 \mathrm{~cm} \times 20 \mathrm{~cm}$ thin-layer plates coated with silica gel. The plates, which had been previously washed and activated, were developed in a system consisting of chloroform, hexane and ethylacetate in proportions of $5: 4: 1$. Areas containing testosterone were scraped off and eluted with methanol and the eluate was

\footnotetext{
* Present address: c/o Dr Jacques Genest, Directeur Scientifique, Clinical Research Institute of Montreal, 110 Avenue des Pins Ouest, Montreal 130, Quebec, Canada.
} 
dried and concentrated with chloroform for a second exposure in the same system. Smaller areas of the testosterone zone were then taken, eluted and made up to a volume of $2 \mathrm{ml} ; 0.5 \mathrm{ml}$ samples were taken for recovery estimations in a Packard Tri-Carb Spectrometer with a 54\% efficiency for tritium.

Testosterone-binding globulin was obtained from late pregnancy plasma and used in a $1 \%$ dilution with distilled water and phosphate buffer, $\mathrm{pH} 7 \cdot 4$. Tritiated testosterone was added to give a count of 14,000 counts $/ \mathrm{min} / \mathrm{ml}$ diluted plasma. The conditions for equilibration were those described by Maeda, Okamoto, Wegienka \& Forsham (1969). A standard curve ranging from 0 to $5 \mathrm{ng}$ testosterone was included with each assay. The reproducibility of the standard curve was consistent.

After incubation of each plasma extract with $1 \mathrm{ml}$ of the late pregnancy plasma dilution, Florisil ( 60 to 100 mesh, Floridin Co.) was added by means of an automatic dispenser and agitated for $30 \mathrm{sec}$. The mixture was centrifuged and $0.5-\mathrm{ml}$ aliquots were taken for counting. The scintillation fluid was the

Table 1. Plasma testosterone levels in normal male, normal female and intersex goats

\begin{tabular}{c|c|c|c|c|c}
\hline \multicolumn{2}{c|}{ Males } & \multicolumn{2}{c|}{ Females } & \multicolumn{2}{c}{ Intersex } \\
\cline { 2 - 6 } \cline { 5 - 6 } Animal no. & $\begin{array}{c}\text { Testosterone } \\
(\text { ng/100 ml })\end{array}$ & Animal no. & $\begin{array}{c}\text { Testerone } \\
(\mathrm{ng} / 100 \mathrm{ml})\end{array}$ & Animal no. & $\begin{array}{c}\text { Testerone } \\
(\mathrm{ng} / 100 \mathrm{ml})\end{array}$ \\
\hline 301 & 766 & 105 & 37 & 155 & 566 \\
262 & 768 & 200 & 132 & 302 & 440 \\
88 & 443 & 217 & 32 & 259 & 340 \\
250 & 814 & 177 & 134 & 170 & 371 \\
313 & 635 & 149 & 98 & & \\
292 & 615 & 272 & 84 & & \\
293 & 315 & 192 & 196 & & \multicolumn{2}{|c}{$429 \pm 100$} \\
\hline
\end{tabular}

The testosterone values are the mean of duplicate estimations.

usual mixture of toluene, PPO and POPOP. Since testosterone was backextracted into toluene, no emulsifying agent was used to create a one-phase system.

Reliability criteria were met as expressed below. Water blanks were usually less than $0.2 \mathrm{ng}$ and were not subtracted. To test precision and accuracy, a 60$\mathrm{ml}$ pooled plasma sample from male goats was extracted and the testosterone levels were measured by gas-liquid chromatography by the method of Goldfien, Jones, Yannone \& White (1965) in a Hewlett Packard 5750 Research Chromatograph. The values obtained were not significantly different from the ones obtained with the present method. When 4 and $8 \mathrm{ng}$ testosterone were added to water, the recovery was $4 \cdot 1 \pm 0 \cdot 3 \mathrm{ng}$ and $8 \cdot 2 \pm 0 \cdot 3 \mathrm{ng}$ (mean and S.D. of triplicates). Plasma samples from gonadectomized, adrenalectomized animals gave similar results. Specificity was tested by examining the behaviour of substances with a binding capacity competing with testosterone. The separation of the competing steroids was accomplished with two thin layer chromatographs. The $R_{F}$ values for some of these steroids were: progesterone, 0.65 ; androstene- 
dione, 0.54; androstanolone (DHT), 0.47; dehydroepiandrosterone (DHEA), 0.48 ; testosterone, 0.35 ; androstenediol, 0.27 .

Final values were corrected for losses. The results obtained are shown in Table 1.

Standard curves were not rectified by logarithmic transformation since this may not be the best fit to experimental data in competitive protein binding for steroids (Leclerq, Täljedal \& Wold, 1971).

Other studies in intersex goats revealed an XX chromosomal pattern and after extensive determinations no mosaicism was detected. Although blood testosterone determinations were performed in only four cases and no normal values were given, results from 'spermatic' blood seem to agree with the view that testosterone originates in the testis (Hamerton, Dickson, Pollard, Grieves \& Short, 1969).

It has been postulated by Jost (1955) that the fetal testis secretes two kinds of hormones; an androgen, possibly testosterone, which stimulates the Wolffian ducts and causes development of the external genitalia and a second substance that inhibits the formation of Müllerian ducts. It is difficult to establish if these substances were secreted in a correct ratio in the intersex animals since androgenization was almost complete, as shown by the male phenotype and sexual behaviour. Only the external genitalia and Wolffian ducts were defective; the uterus and Fallopian tubes were well developed.

The plasma testosterone levels found in the intersex animals were significantly greater than those in the normal females. These levels of testosterone could explain some of the features of the intersex animals but are puzzling in the context of a testosterone-secreting structure coexisting with a uterus and Fallopian tubes in the absence of ovaries. The testosterone in the intersex goats possibly originated in the testis-like structures found at the time of autopsy.

The testosterone values for the 'normal' goats were obtained only in order to have terms of comparison for the intersex animals and no attempt should be made to generalize from the results since the number of animals involved was small.

The animals in the present studies were either singletons or had a female litter-mate. The possibility of 'freemartinism' could therefore be discarded. The testosterone values for the females were slightly higher than were expected. Whether these values reflect a biased selection of the so-called 'normal' females or an error inherent in the method when measuring low levels of testosterone is still to be elucidated.

The interpretation of the findings of the present study would imply that at the time of fetal morphogenesis, no Müllerian inhibitor was present and, therefore, no normal testis was present. The testosterone-secreting structure must have appeared later during development. Whether the original structure was an ovary which later disappeared owing to a sex reversal during development, or whether a genetically defective testis failed to inhibit the development of Müllerian ducts, has yet to be established.

The possibility of a testis with a normal testosterone-secreting capacity and abnormal Müllerian duct-inhibiting function may be an alternative possibility. In this case, an early defect of testosterone production by the fetal testis or a 
transient lack of target-organ response in these genetically XX animals has to be postulated to explain the incomplete virilization of the external genitalia and the absence of vasa deferentia and seminal vesicles in the animals used in this study.

Finally, the use of data obtained from experiments with rodents should not be utilized indiscriminately to explain sexual differentiation in other mammals. Since intersex animals are a fairly common finding in this colony, further studies will be undertaken.

The author is indebted to Professor $\mathrm{Dr} \mathrm{W}$. Ladosky for performing the autopsies and to Mr Luiz Treicicki for his technical assistance. Chromosomal and sex chromatin studies were performed by Dr Wilham Jorge, as part of a genetic study of the colony. This work was supported in part by funds from the National Research Council of Brazil and Grant M70.142C from The Population Council of New York.

\section{REFERENGES}

August, G. P., Tkachuk, M. \& Grumbach, M. M. (1969) Plasma testosterone-binding affinity and testosterone in umbilical cord plasma, late pregnancy, prepubertal children, and adults. $\mathcal{F}$. clin. Endocr. Metab. 29, 891.

Goldfien, A., Jones, J., YAnnone, M. E. \& White, B. (1965) The estimation of plasma androgens by gasliquid chromatography. In: Proceedings of the Workshop on Gas-Liquid Chromatography of Steroids in Biological Fluids. Ed. M. B. Lipsett. Plenum Press, New York.

Hamerton, J. L., Digkson, J. M., Pollard, C. E., Grieves, S. A. \& Short, R. V. (1969) Genetic intersexuality in goats. 7. Reprod. Fert. Suppl. 7, 25.

Jost, A. (1955) Modalities in the action of gonadal and gonad-stimulating hormone in the foetus. Mem. Soc. Endocr. 4, 237.

LEClere, R., TÄLJEDAL, I. B. \& Wold, W. (1971) Evaluation of radioisotope data in steroid assays based on competitive protein binding. Clinica chim. Acta, 36, 257.

Maeda, R., Okamoto, M., Wegienka, L. G. \& Forsham, P. H. (1969) A clinically useful method for plasma testosterone determination. Steroids, 13, 83. 